\title{
Speech Levels in Open Plan Offices
}

\author{
A.C.C. Warnock ${ }^{1}$, W.T. Chu ${ }^{1}$ \\ ${ }^{1}$ Institute for Research in Construction, National Research Council Canada, 1200 Montreal Road, Ottawa, KIA 0R6, \\ alf.warnock@nrc.ca
}

\section{INTRODUCTION}

A key variable for predicting speech privacy in open offices is the loudness of speech in such spaces. Since the environment influences how loudly we speak, speech levels need to be measured in typical open office situations so they can be used to calculate speech privacy expected there more accurately. The most extensive set of data on speech levels is that in the report by Pearsons et $\mathrm{al}^{1}$. The mean spectrum for "normal conversational speech" from that study was incorporated into ASTM $1130^{2}$ for estimating speech privacy in open plan offices. A more recent study ${ }^{3}$ agreed fairly well with that of Pearsons. However, it is not obvious that "nomal" voice levels are appropriate for open offices.

\section{DATA COLLECTION}

Measurements of voice levels used in face-to-face conversation were made in nine open offices in the Ottawa/Hull Area on behalf of Public Works and Government Services Canada (PWGSC).

Subjects were asked to wear a headset microphone and to speak as naturally and freely as they normally would in their workstation to a person sitting next to them (the interviewer). The speech was to last for I minute without interruption. Any topic could be chosen. To help with making a choice, four suggestions were provided: their job, their last holiday, the town they grew up in, or the route they take to work in the morning. The monologue could be in French or English. The same interviewer was used at each site. The voices recorded were recorded on a calibrated digital tape recorder and later analyzed in the laboratory using a 1/3 octave-band real time analyzer. Using a 30 second segment of the recording and an integration lime of $1 / 16$ second, a total of 480 samples were obtained for each $1 / 3$-octave band from $160 \mathrm{~Hz}$ to $8 \mathrm{kHz}$. From this information, mean, $\mathrm{L}_{1}, \mathrm{~L}_{10}, \mathrm{~L}_{50}, \mathrm{~L}_{90}$, and $\mathrm{L}_{\mathrm{eq}}$ were calculated in each band. A calibration procedure was used to convert to levels $0.9 \mathrm{~m}$ in front of the talker.

\section{RESULTS}

The distribution of average A-weighted sound pressure level for each subject measured in the nine office sites is shown as a histogram in the Figure 1. There is a peak at $5 \mathrm{IdBA}$ for the male group, whereas the dominant levels for the female group spread from 47 to $53 \mathrm{dBA}$. For all subjects, the average male and female voice levels were $51.3 \mathrm{dBA}$ and $50.6 \mathrm{dBA}$ respectively.

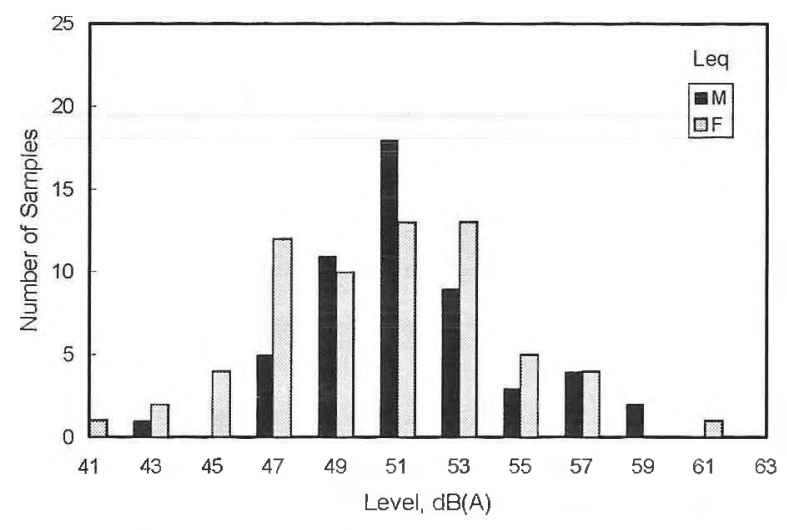

Figure 1: Distribution of A-weighted speech levels, dBA, for the 118 subjects in the nine open plan offices.

Figure 2 compares the mean long-term average $1 / 3$ octaveband speech levels from all 118 subjects with the spectra given by the ANSI ${ }^{4}$ and ASTM standards. Results from the current study are significantly lower than those given by the standards. A probable explanation is that the current study used conversational speech with two people sitting close together whereas the ASTM standard and possibly the ANSI standard used levels based on subjects reciting fixed texts and being asked to speak in a "normal" voice. Also shown in Figure 2 are Pearsons' results for "casual conversation". They agree well with the current results.

The A-weighted levels for each of the curves in Figure 2 are given in the following table.

\begin{tabular}{|l|l|}
\hline This study & $50 \mathrm{dBA}$ \\
\hline ANSI S3.5 & $59 \mathrm{dBA}$ \\
\hline ASTM E1 130 & $57 \mathrm{dBA}$ \\
\hline Pearsons Casual & $50 \mathrm{dBA}$ \\
\hline
\end{tabular}

These differences in voice level lead to quite large differences in Speech Intelligibility Index and therefore speech privacy.

In the same offices measurements of propagation were made between workstations. Assuming a background noise level of $45 \mathrm{dBA}$ and the ASTM E1130 voice spectrum, values of 
Speech Intelligibility Index (SII) and Articulation Index (AI) were calculated for each workstation pair. The relationship found between the two ratings was

$$
\mathrm{SII}=1.03 \mathrm{AI}+0.06, \mathrm{r}^{2}=0.997 \text {. }
$$

Calculations in E1130 are made using fewer frequency bands than in ANSI S3.5. Since the correlation between SII and AI was found to be so high, ASTM E33 decided not to change E1130.

$\mathrm{AI}=0.15$ ( $\mathrm{SII}=0.2)$ is commonly taken as the upper limit for normal privacy in open offices. With an assumed $45 \mathrm{dBA}$ background spectrum and the voice levels in E1130, only about $10 \%$ of the occupants would experience $\mathrm{AI} \leq 0.15$. If instead the measured average voice level is used, about $50 \%$ of the occupants would experience $\mathrm{AI} \leq 0.15$.

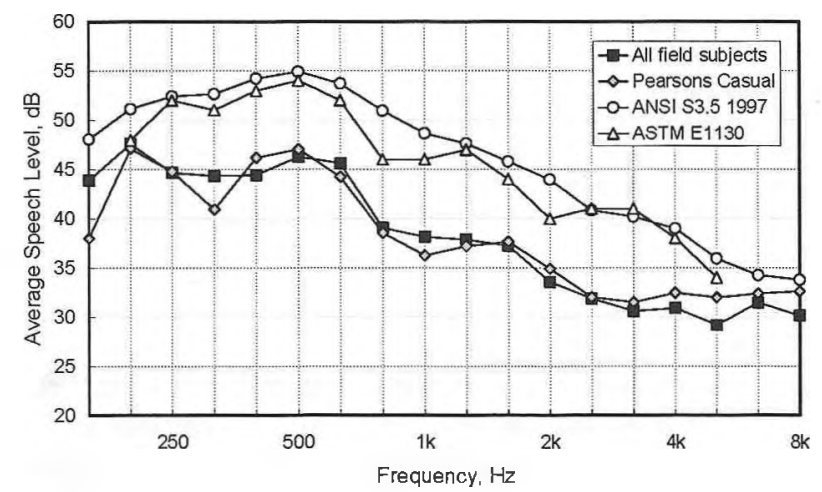

Figure 2: Comparison of the mean average 1/3 octave-band speech levels at $0.9 \mathrm{~m}$ in front of the talker.

ASTM E 1130 and ANSI S3.5 give the difference between the peak and the $\mathrm{L}_{\mathrm{eq}}$ speech levels in each 1/3-octave band as $12 \mathrm{~dB}$. Results from the current study are shown in Figure 3. With the exception of a few low-frequency bands, all the differences are significantly greater than $12 \mathrm{~dB}$ although the A-weighted differences are close to 12 .

\section{COMMENTS}

The speech levels were measured when the subjects were speaking to an interviewer sitting less than 1 metre away. They are not appropriate for conversations with co-workers at distances of 3 or 4 metres. It is thought that average voice levels used during telephone conversations are not likely to be very different from those measured in this project but further measurements would be needed to verify this assumption.

Observations in the offices during the recordings supported common experience that the voice level used depends strongly on factors such as the distance between the talker and the listener and the subject of the conversation. Office etiquette can also be a factor. If there is continual social pressure from co-workers to speak quietly, just as in a library setting, then one can expect less annoyance from intrusive speech. A study of behaviour in open offices might lead to procedures to control intrusive speech that are at least as effective as extensive use of barriers and sound absorbing materials.

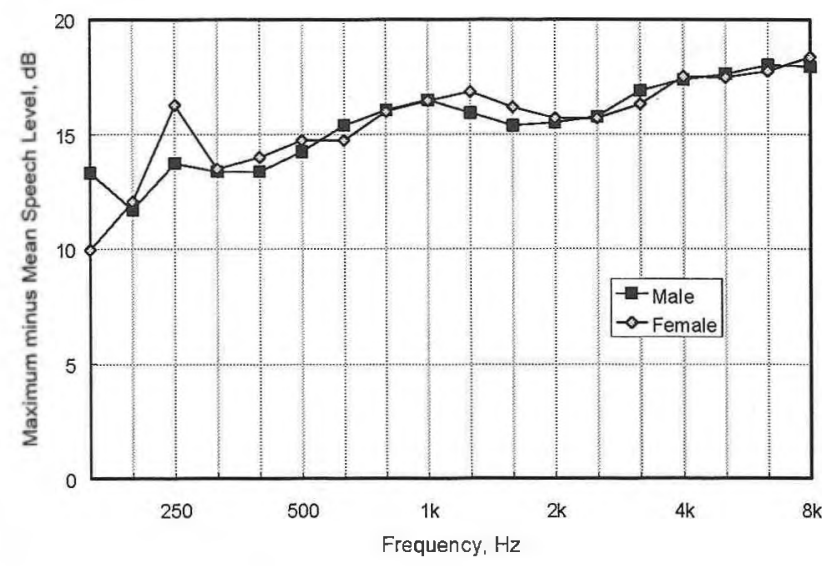

Figure 3: Average difference between the peak levels and the $L_{e q}$ levels for the male and female groups. The difference between the average $\mathrm{A}$-weighted $\mathrm{L}_{\text {eq }}$ and the average $\mathrm{A}$-weighted peak values was $12.3 \mathrm{dBA}$ for males and 12.2 $\mathrm{dBA}$ for females.

The details of the work are available in an IRC internal report ${ }^{3}$.

\section{ACKNOWLEDGEMENTS}

This work was supported by Public Works and Government Services Canada.

\section{REFERENCES}

${ }^{1}$ Pearsons, K.S., Bennett, R.L., and Fidel, S., "Speech Levels in Various Noise Environments," EPA-6001-77-025, U. S. Environmental Protection Agency, May 1977, p. 39. Available from National Technical Information Services as No. PB-270 053.

${ }^{2}$ ASTM E1130 Standard test method for objective measurement of speech privacy in open offices using articulation index.

${ }^{3}$ McKendree, F.S., "Directivity indices of human talkers in English speech," Proceedings of Inter-Noise 86, pp. 911-916, July 21-23, 1986.

${ }^{4}$ ANSI S3.5 American National Standard Methods for the Calculation of the Speech Intelligibility Index.

${ }^{5}$ Warnock, A.C.C. and Chu, W.T. "Voice and Background Noise Levels Measured in Open Offices," IRC Internal Report IR-837, January 2002. 